\title{
Enlightenment of Qilou Street Space Intelligence to Pedestrian System Design in Commercial District \\ Jing $\mathrm{CHEN}^{1, a,{ }^{*}, \text { Fang WANG }}{ }^{2, b}$, Jia-Ping LIU ${ }^{3, c}$
}

\author{
${ }^{1}$ Xi'an University of Architecture and Technology, Landcape Architecture Post-doctoral research \\ station, Xi'an 710055, China \\ ${ }^{2}$ Xi'an University of Architecture and Technology Rural and urban planning Post-doctoral research \\ station, Xi'an 710055, China \\ ${ }^{3}$ Xi'an University of Architecture and Technology college of Architecture, Xi'an 710055, China \\ a511628491@qq.com, b'wangfangjzfly@163.com, cliujiaping@yahoo.com \\ ${ }^{*}$ Corresponding author
}

Keywords: Qilou, Commercial Districts, Pedestrian System Design.

\begin{abstract}
Aiming at those generally existing problems in urban commercial pedestrian districts, through the design methods of extracting separation of man from vehicle in traditional Qilou pedestrian street space, continuous pedestrian space with shelter, and the behavior paths with combination of commercial activities, this thesis sets about from the behaviors of pedestrians in walking state, and finds that the traditional Qilou pedestrian street space can satisfy pedestrians' physiological and psychological demands in shopping better. At the same time, combining current urban commercial districts developing demands, and the successful experience from traditional Qilou, this thesis also proposes relevant improvement measures. The improvements in design means are expected to improve pedestrian environment for, and achieve the commercial values of these districts, as well as the win-win of environment improvement and commercial activity development.
\end{abstract}

\section{Introduction}

Urban commercial districts often located in some important core district of city where many people will gather together. The get-together of large numbers of pedestrians causes a series problems, such as disordered site, traffic disturbance, bad environmental quality, etc., and all these problems have been presented intensively in pedestrian space system of commercial districts. For a long time, the pedestrian system design of urban commercial districts includes two classifications: The first is the pedestrian system space with primary of complete pedestrian streets. This kind of pedestrian system can separate traffic flows out of pedestrian system, which can relieve the pressures to pedestrian streets by motor vehicles, and enhance the security of pedestrian streets. However, it also brings negative effects that block unban road traffic, increase pressures of those roads around pedestrian streets, and also influence nearby residents' going-out. At the same time, as some regions are deeply influenced by local special climatic conditions, efficiency of some pedestrian streets actually cannot be given full play. The second is the common pedestrian streets in general commercial districts, which has no significant differences with those ordinary urban streets, and it is only the sidewalk outward of commercial buildings in the space lay. This kind of pedestrian street is short of professional design, and except can satisfy essential traffic function, has few attractive effects to pedestrians by pedestrian space. Therefore, the values of commercial buildings cannot be expressed through pedestrian streets. In allusion to above two circumstances, we will proceed with analyzing commercial activities of pedestrians, and it is crucial to excavate successful experience of traditional commercial pedestrian streets.

\section{Analysis of Pedestrians' Behavior Psychology in Commercial Pedestrian Districts}

\section{Security}

The security of commercial pedestrian districts is a primary problem concerned by every waling 
shopper. The Global Situation Report of Road Safety 2013 reveals that the number of people who die of road traffic accidents annually in the world reaches up to 1.24 million, among 270,000 of which are pedestrians, accounting for $22 \%$ of the total death toll for road transportation safety. The security problems of commercial pedestrian roads mainly concentrate upon coexistence of people and vehicles, signal lamp faults, unreasonable street crossing safety facilities set, unreasonable connection of pedestrian walkway and public transportation facilities, etc. As no consideration of growth rate of motor vehicles are taken into the design of some commercial districts, and at the later stage, roadways was broadened by occupying sidewalk blindly, it is easy to give rise to the complexion of people and vehicles coexistence. While some street roads are excessively wide and the waiting time for automobiles is too short in signal lamp design, all will lead to condition of snatching path by pedestrians and automobiles. It is quite dangerous for the disabled, the aged with mobility problem and children with weak transportation safety awareness.

\section{Comfort}

The comfort problem of commercial pedestrian districts is an important issue in pedestrian system design. At present, most are open type of pedestrian systems in commercial districts, and pedestrians mainly proceed along sidewalk. Two problems often will be neglected in the design of such open type of pedestrian system: 1. Behavior comfort of users. For the open type of pedestrian system, it can satisfy pedestrian comfort demands in specific time periods (such as early morning or dusk), while it cannot satisfy essential usage requirements with the effects of burning sun and intense fall within considerable time. 2. Psychological comfort of users. The pedestrian system design without support of building and environment is faced with some problems, such as hot weather, noisy surroundings, dusts all over the sky, waste water overflowing, excessively serried pedestrians, etc. Even though this pedestrian space can satisfy peoples' basic usage requirements, it cannot meet their sensory demands.

\section{Convenience}

Due to the uncertainty of pedestrians' behaviors, the behavioral purposes of those who are in a same road can be different. While in most cases, the diversity of people's pedestrian habits doesn't be taken into consideration by the pedestrian system in commercial districts, and the walkways are only developed into the means for traffic. For how to pass through urban streets conveniently and safely, how to enter into public traffic system conveniently and safely, how to distinguish traversing pedestrian stream and staying pedestrian stream in a same district in case of pedestrian congestion, and how to care for the disabled and those with mobility problems, this system still has no sufficient consideration. Some relevant data indicate that, if only passenger foot-bridge and tunnel are available for pedestrians to cross streets, $24 \%$ of pedestrians will give up street crossing, and $39 \%$ of them will reduce times of crossing streets ( $48 \%$ for the aged). Likewise, the arbitrary occupation of sidewalks for the blind, unreasonable public facilities set and several factors also bring more incommodities to the service of pedestrian space.

\section{Affinity}

Except a small number of specific commercial pedestrian streets, the business interface analysis along the streets in the pedestrian systems of most urban districts is relatively random, and business interfaces don't have a strong affinity to pedestrians. Business interface and urban pedestrian system are two separated systems, and buildings are separated with sidewalks by outer walls. The pedestrians usually pass by a hurried glance under the burning sun, except they have certain purposes to commercial space. Business interface and sidewalks lack a kind of bias relation.

\section{Randomness}

When pedestrians enter into commercial districts, most of them won't have obvious purpose. But with the attractions of commodities, advertisements, promotion performance and other outer commercial activities, or the external disturbances from weather, motor vehicles and construction activities, pedestrians often will not proceed upon the path schemed in original commercial 
pedestrian streets, but will select their routes upon their own subjective ideas.

\section{Experience}

In today's rapid development of E-commerce, consumption activities have not been limited to the simple service modes, like "home delivery service", and now people hope to actively engage in it to acquire distinctive feelings and various integrity experiences, as well as make pleasant memories that are difficult to be forgotten. Consumers are not content with the single consumption experiences of "Window Shopping", but desire to enhance experiences through all-around participation of visual sense, taste sense, smell sense and auditory sense, to make full sense of urban cultural connotation.

\section{The Intelligence of Traditional Qilou Street to Answer Commercial Activities}

Qilou was a typical urban street and architectural form at the end of $19^{\text {th }}$ century and the beginning of $20^{\text {th }}$ century. The extensive development in China's South-East coastal areas for nearly 100 years explains that Qilou buildings and streets have a strong geographical adaptability. As the typical residential office building types, Qilou usually presented to core commercial districts cities and towns then. Although the commercial industry and building type of these commercial districts had a great difference with today's urban commercial districts, the consumer psychology of those pedestrians in commercial districts in recent years was similar. The extraction of Qilou street pedestrian space intelligence will be conducive to recognize the relations between human behaviors and pedestrian space.

\section{Explicit Space of Separation of Man from Vehicle}

Although at the beginning of constructing Qilou, the quantity of automobiles was much less than that of today, while urban planning, the relations between Qilou sidewalks and urban main streets has been taken into consideration. For example, in the 1920s, Guangzhou city Municipal Office take arrest building 15 feet wide arcade charter issued by Guangzhou City had the stipulations that the streets of 100 feet ( about $30 \mathrm{~m}$ ) can be constructed with 20 -feet-width (about $6.1 \mathrm{~m}$ ) Qilou, and 80 feet (about $24.4 \mathrm{~m}$ ) streets can be constructed with 15 -feet-width (about $4.6 \mathrm{~m}$ ) Qilou. The traffic layout which divided urban traffic trunk road and footpath will be helpful to separation of pedestrian and vehicles. Through the research to domestic existing Qilou streets, we can find that: the main reasons Qilou street separating pedestrian and vehicles are as following: (1) There's 10 20 $\mathrm{cm}$ height difference between roadway and walkways, it limits clearly on the border between roadway and walkways. (2) Due to narrow footpath, if the car park at footpath, it will hinder the pedestrian traffic. (3) Continuous colonnade at footpath will hinder car for entering. (4) Peddlers who are along the outside of Qilou Street (near the roadway) will hinder vehicles closing. To sum up, Qilou building has separated pedestrians and motor vehicles clearly and ensured pedestrian traffic safety in the walking process (Fig.1).

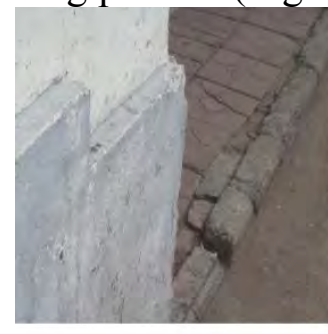

relative elevation

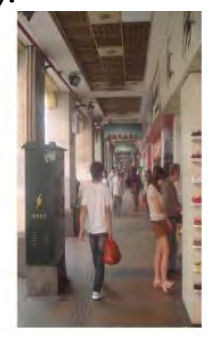

colonnade and Walkway scale

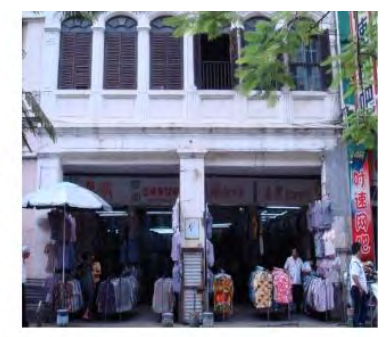

Street vendors

Fig. 1 the Ways of Separation of Man from Vehicle

\section{Continuous Sheltered Pedestrian Space}

Another wisdom of Qilou Street lies in that it forms continuous semi open space through continuous side-by-side buildings. This kind of continuous shelter space ensures pedestrians can 
pass in the internal space no matter in hot sun or in the wind and rain. It changed the situation that people have to hide inside the building for lacking of covering measures and it provides more possibilities for pedestrians to do outdoor activity under special climate conditions.

\section{Behaviors Linked with Commercial Activities}

Qilou building as a residential and commercial amphibious model building, its business development has strong link with traffic layout. (1) Pedestrian space of Qilou Street has shortened the distance of pedestrians and shops. Influenced by external climate and traffic, mostly pedestrians walk on walkway less than $3 \mathrm{~m}$. Often many pedestrians are walking by stores, it's better for them to find and realize what's in it. Interface along the street adopts the open stance. Most of Qilou commercial buildings use the completely open mode. Pedestrians can understand internal operating conditions at a glance passing by and easily enter in. those enclosed, limited gateway of commercial space cannot compare with it. (3) Commercial industry is developed in linear form rather than centralized distribution, thus it can avoid the strong purposeful centralized shopping mode usually at mall and bring positive influence to development of experiential business model (Fig.2).

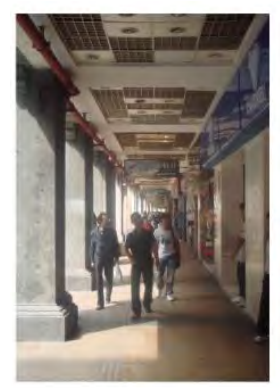

Open commercial interface

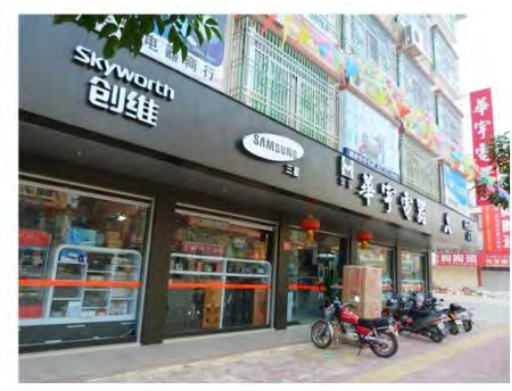

Closed commercial interface

Fig.2 Open and Closed Commercial Interface

\section{The Way Integrated Traditional Wisdom of Qilou and Commercial Pedestrian System}

\section{Add Continuous Pedestrian Space with Shelter}

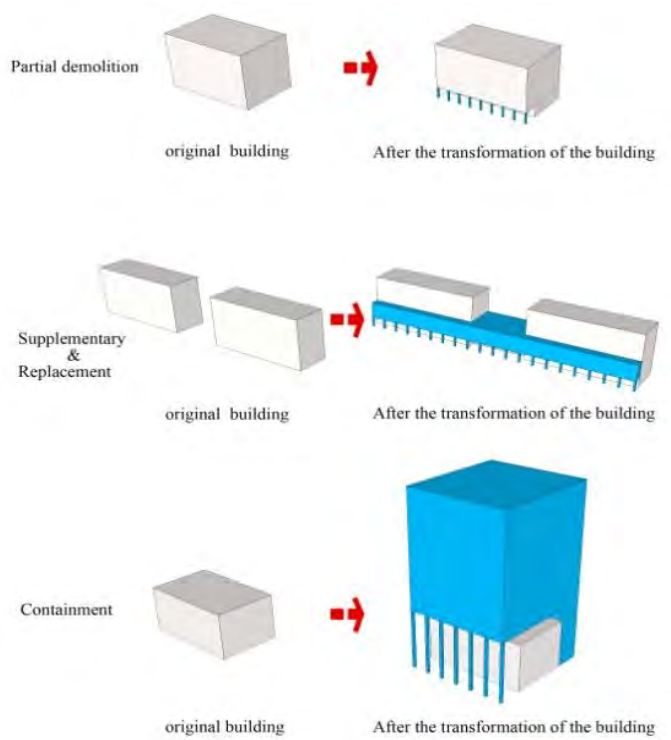

Fig.3 Transform Ways of Existing Buildings

For pedestrians, physical and psychological comforts are the first issue should be met during shopping. however, in the contemporary urban business district, buildings and roads are often disjointed and lack necessary linking, so pedestrian will pick up comfortable period (such as 
evening), or at the day time with purpose to enter certain mall rather than stay under strong sunlight pedestrian path. Enhance, in order to increase stream at daytime and extend their stay, it's necessary to stop the influence to pedestrian system by vehicles and transform interface along the street of original commercial buildings. The transformation mainly involves two aspects: (1) transformation on interface along the street. Back and leave some space of original commercial space interface to realize better pedestrian space with shelter. (2) Add vestibule with shelter between building and building. Due to the limitation of current requirements for fire protection and actual construction situation, it's difficult to realize continuous of hundreds of meters pedestrian street space with ceiling. In hence, it should link the pedestrian space by setting of vestibules appropriately (Fig.3).

\section{Broaden the Scale of Walking Space}

Influenced by rules and regulations and its building structure system, traditional Qilou building usually has a spatial scale at width of $2.1 \sim 3 \mathrm{~m}$ and height of $4 \sim 5 \mathrm{~m}$. This kind of space can satisfy the need of $2 \sim 3$ streams of people. Due to the narrow space, it's difficult to increase people, other service facilities and to expand using function. Of course, modern commercial development requires a lot of pedestrians and at the same time, the progress of structural technology can offer the guarantee. Assuming that the standard column grid used by current market is $8 \mathrm{~m}$, one column space back to street will form the $8 \mathrm{~m}$ wide pedestrian street space. Under this space, it not only can increase more service facilities, but also attracts more people to commercial interface. Meanwhile, it's possible for the vertical transport facilities with this width. For example, increase the height of Qilou building to 2 or 3 floors, it can lead pedestrians to floor 2 or 3 with escalator, thus it will increase the passenger flow of intervention (Fig.4).

\section{Perfect External Connection Way of Pedestrian System}

Semi open space of Qilou Pedestrian Street and city vehicles system are isolated and interpenetrative. On the one hand, vehicles have been isolated from pedestrian system and on the other hand, pedestrians can easily enter into motorway, it provides lots of conveniences for linking of public facilities and pedestrian system. For example, people want to take public transportation, they have to walk through the bike lanes and then wait at the narrow waiting room. Under sun and rain, it often cannot meet the needs of a large number of passengers. While in Qilou Pedestrian Street, its width and continuous space can accommodate lots of passengers. At the same time, Qilou Pedestrian Street with a certain width can offer convenient access for metro.

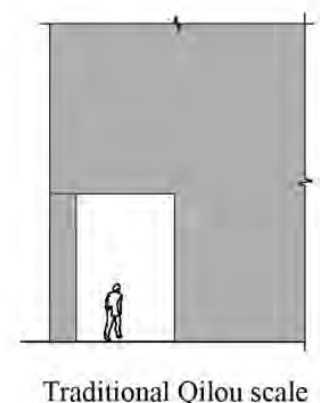

Traditional Qilou scale

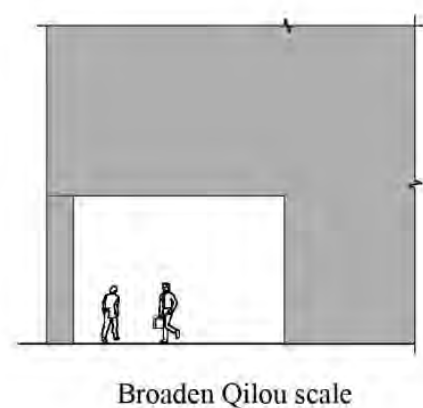

Broaden Qilou scale

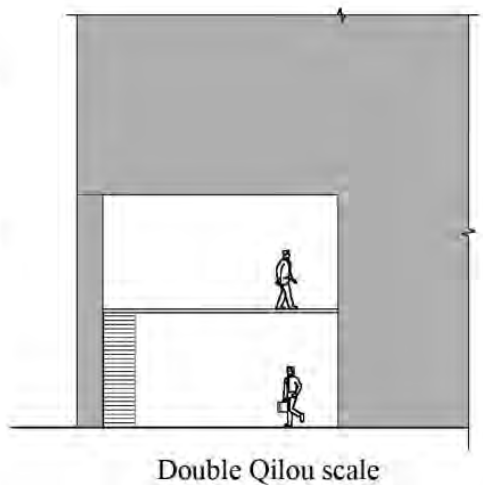

Double Qilou scale

Fig. 4 Broaden the Scale of Walking Space

\section{Perfect the Service Facility in Pedestrian System}

Another important supporting factor is the perfect service facilities. Service facilities can be divided into service facility for rest, hygiene service facility, orientation and informational services and service facilities for pleasure and sightseeing (Table 1). In addition of those people who have purpose of passing through, most of pedestrian with weak objective need facilities to meet the needs of comfort and novelty. 
Tab. 1 Service Facility in Pedestrian System

\begin{tabular}{l|l|l}
\hline Item & Content & Function \\
\hline $\begin{array}{l}\text { Service facility for } \\
\text { rest }\end{array}$ & seat & Meet the needs of rest and waiting \\
\hline $\begin{array}{l}\text { Hygiene service } \\
\text { facility }\end{array}$ & Trash, waste recycling & $\begin{array}{l}\text { Keep the street hygienic; recycle garbage can be } \\
\text { recycled; }\end{array}$ \\
\hline $\begin{array}{l}\text { Orientation and } \\
\text { informational } \\
\text { services }\end{array}$ & $\begin{array}{l}\text { road sign, house } \\
\text { number, billboard }\end{array}$ & $\begin{array}{l}\text { Hint the information of places, roads and traffic } \\
\text { site }\end{array}$ \\
\hline $\begin{array}{l}\text { Service facilities } \\
\text { for pleasure and } \\
\text { sightseeing }\end{array}$ & $\begin{array}{l}\text { sculpture, sketch, } \\
\text { greenery landscape, } \\
\text { display space }\end{array}$ & $\begin{array}{l}\text { Beautify road environment, show regional culture } \\
\text { and strengthen the business promotion. }\end{array}$ \\
\hline
\end{tabular}

\section{Conclusion}

Qilou pedestrian street space as the rudiment of modern commercial pedestrian system developed in China, despite its size, functions, forms still cannot meet the needs of commercial development in urban core areas, but it starts from mental shopping need of pedestrian and fully takes requirements of pedestrian mental activity into consideration and satisfy it through the way of building, the successful experience is worth studying. Extracted experience from traditional Qilou pedestrian space can be integrated into demand of current business district development, through improvement of design means, it can meet the psychological demand of pedestrians in pedestrian shopping also maximize the interests.

\section{Acknowledgement}

The research described in this paper was supported by science and technology talents fund of Xi'an University of Architecture And Technology (RC1301) \& the National Natural Science Foundation of China (Grant No. 51408470, 51221865, 51178369).

\section{References}

[1]The Chinese people's political consultative conference news.1/4 of traffic accident death toll is pedestrian in China [EB/OL].http:// cppcc.people.com.cn/n/2013/0508/c34948-21401476.html, 2013-05-08. [In Chinese]

[2]Cao Guozhang, Yang Xiaoxiang. Study on walking street culture in the experience economy stage [J]. Huazhong Architecture, 2010(11):163-165. [In Chinese]

[3]Huang Sujuan. Guangzhou Qilou's regulations and practice in the period of the republic of China [J] Academic Research, 2013(3):123-133. [In Chinese]

[4]Chen jing. Haikou Qilou regional adaptability model research [D].Xian: Xian University of architecture\&technology, 2012:164-165. [In Chinese] 